\title{
Epidemiology of genitourinary foreign bodies in the united states emergency room setting and its association with mental health disorders
}

\author{
Dayron Rodríguez ${ }^{1} \cdot$ Nannan Thirumavalavan ${ }^{2} \cdot$ Shu Pan $^{1} \cdot$ Michel Apoj ${ }^{1} \cdot{\text { Mohit Butaney } \mathbb{D}^{3} \cdot \text { Martin S. Gross }}^{4}$. \\ Ricardo Munarriz ${ }^{1}$
}

Received: 24 May 2019 / Revised: 5 June 2019 / Accepted: 21 June 2019 / Published online: 10 September 2019

(c) The Author(s), under exclusive licence to Springer Nature Limited 2019

\begin{abstract}
The epidemiology of genitourinary foreign bodies (GUFB) has been mainly described through case reports and small series. The aim of this study is to investigate the epidemiologic, medical, and socioeconomic factors associated with GUFB, along with the resultant costs of care in emergency departments (EDs) nationwide. ED visits with the primary diagnosis of a GUFB between 2010 and 2014 were abstracted from the Nationwide Emergency Department Sample database. Between 2010 and 2014, a weighted estimate of 102,333 visits to the ED with GUFB were recorded in the US, representing a national incidence of 7.6 ED visits per 100,000 persons. Of these visits, $4.7 \%$ resulted in admission and males were more likely to be admitted ( $24.8 \%$ vs. $2.1 \%, p<0.01)$. A third of patients had low income, $30 \%$ had no medical insurance, and a third of patients had Medicaid. Urethra/bladder and penile foreign bodies had a significant association with mental health disorders (35.6\%). Vulvar/vaginal foreign bodies had a lower prevalence of mental health disorders (6.1\%). Costs of managing patients in the ED averaged $\$ 3769$. More importantly, penile or urethra/bladder foreign bodies incurred a higher cost $(\$ 30,071)$. This is the largest population-based study investigating the epidemiology of GUFB. GUFB are more common in young women and the majority of them are vulvar/vaginal. Urethral and bladder foreign bodies occurred in older male patients and are associated with longer hospital stays and costs. Over one third of male patients with urethra/bladder had significant mental health disorders.
\end{abstract}

\section{Introduction}

Genitourinary foreign bodies (GUFB) presenting to the emergency department (ED) often require urologic and gynecologic consultations, invasive interventions

Supplementary information The online version of this article (https:// doi.org/10.1038/s41443-019-0194-z) contains supplementary material, which is available to authorized users.

\section{Ricardo Munarriz}

munarriz@bu.edu

1 Department of Urology, Boston University School of Medicine, Boston, MA 02118, USA

2 Department of Urology, University Hospital, Case Western Reserve School of Medicine, Cleveland, OH 44106, USA

3 Department of Urology, Mayo Clinic, Rochester, Seattle, WA 98195, USA

4 Section of Urology, Department of Surgery, Dartmouth-Hitchcock Medical Center, One Medical Center Drive, Lebanon, NH 03756, USA (cystoscopy, vulvoscopy, exam under anesthesia, etc.), and on occasion hospital admissions. In addition, GUFB may be associated with complications and long term sequelae (urethral false passages, bleeding, infection, fistulas, stricture formation, etc.) and represent a cost burden to the healthcare system in the United States [1]. Foreign bodies have been well studied in the gastrointestinal and respiratory systems, but the genitourinary literature is limited [2,3]. The epidemiology and management of GUFB have been mainly described through case reports, technique papers, and small series [4-7]. Van Ophoven et al. published the largest review of cases and it consisted of 800 different case reports [8]. There is a lack of systematic assessment of GUFB in the urgent care setting $[1,5,7,9,10]$. In addition, the relationship between GUFB and mental health disorders, which appears to exist anecdotally, has not yet been established. The aim of this study is to investigate the epidemiologic, medical, and socioeconomic factors associated with GUFB, and the resultant costs of care in EDs nationwide. We also further 
examined the association of GUFB with mental health disorders.

\section{Materials and methods}

\section{Data source and study design}

This is an IRB exempt, retrospective cross-sectional study of patients presenting with GUFB to the emergency room between 2010 and 2014 (5 years) using the Nationwide Emergency Department Sample (NEDS) [11]. The NEDS is the largest all-payer emergency room database in the United States and includes $\sim 31$ million (unweighted) visits from 953 hospitals across 35 states. It represents $\sim 20 \%$ of the stratified sample of US hospital-based ED encounters and the dataset is weighted to allow population-level estimates of the sampled observations to represent a total of nearly 143 million ED visits in the US each year.

\section{Sample population}

Data from patients with a primary diagnosis of GUFB using the International Classification of Diseases Ninth Revision (ICD-9) code 939.0-939.9 were selected for analysis, resulting in the identification of 22,900 ED visits between January 2010 and December 2014 [11]. For the time period analyzed in our study, the NEDS database used ICD-9, and thus we also used it in our study. For a description of each ICD-9 code and the corresponding anatomic location in the genitourinary tract, please refer to Appendix Table B. Notably, the ICD-9 code of 939.1 was excluded from analysis as it pertains to uterine foreign body, which is indicated by review of literature as predominantly iatrogenic in nature (such as intrauterine devices), and thus beyond the scope of this study $[12,13]$. Weighted population estimates were projected to national levels using discharge stratum weights. Incidences were normalized to population estimates from 2000 U.S. Census data. This process yielded a total of 102,333 weighted ED visits for a mean national estimate of 20,467 ED visits per year.

\section{Baseline patient and hospital characteristics}

Age categories were created for female patients $(0-18$, $18-55$, and $>55$ years old) for ease of analysis. These categories were meant to distinguish three groups-pediatric females, premenopausal females, and postmenopausal females (based on the upper end of normal when women experience menopause $\rightarrow 55$ years old). The justification for the age categories in female patients also stems from our literature review showing that the etiology of GUFB in young females differ greatly from older age segments, and sexual abuse should always be investigated as a cause [14]. Male patients were categorized by decades of life. Seasons were defined as follows: winter from January to March, spring from April to June, summer from July to September, and fall from October to December. Low income was defined as having or belonging to a zip code with a median household income in the lowest quartile $(<\$ 39,999)$. Data regarding race disposition was not captured in the NEDS. Low volume hospitals were defined as those with ED visit volume in the lowest quartile. Detailed descriptions of the definitions of hospital characteristics are available in the NEDS documentation: (https://www.hcup-us.ahrq.gov/db/ nation/neds/nedsdbdocumentation.jsp).

The Agency for Healthcare Research and Quality has developed a Mental Health and Substance Abuse Clinical Classification Software (CCS-MHSA). The CCS-MHSA was derived primarily from the Diagnostic and Statistical Manual of Mental Disorders, Fourth Edition, and it is used to aggregate ICD-9-CM MHSA diagnostic codes into a limited number of clinically meaningful categories (https://a rchive.ahrq.gov/data/hcup/factbk10/factbk10appa.htm) [15]. Detailed information on CCS-MHSA and the CCS can be downloaded from the HCUP User Support Web site at: http://www.hcup-us.ahrq.gov/tools_software.jsp. Appendix Table A shows the CCS-MHSA codes used to identify specific mental health disorders. Mental health disorders were present as a diagnosis at the time of presentation to the emergency room. The NEDS provides information on charges for ED services. Supplemental files included total inpatient charges for a proportion of those events that resulted in admission. Hospital total charges per encounter were available for all patients, but these charges did not include professional fees and non-covered charges.

\section{Statistical analysis}

All statistical analyses were weighted to allow populationlevel estimates of the sampled observation. Frequencies and proportions were generated to summarize categorical variables, and the Mann-Whitney and chi-square tests were used to assess the statistical significance of differences in populations. Means and standard errors of the means were used to summarize continuous variables. A chi-square goodness of fit test was used to examine whether season of admission showed an unequal distribution against an expected distribution of one quarter of admissions in each season. A one-sample $t$ test of weighted proportion was used to test whether weekend admission was significant against an expected 2 out of 7 (28.6\%) days representing the weekend presentation group. Statistical analyses were performed with JMP Pro Version 14 (NC, USA) and SPSS Statistical Package Ver 23.0 (IL, USA). A $p$-value $<0.05$ 
was considered statistically significant. All statistical tests were two-sided.

\section{Results}

Between 2010 and 2014 a weighted estimate of 102,333 visits to the ED for GUFB was recorded in the United States, which represents a national incidence of 7.6 per 100,000 subjects per year $( \pm 0.061 \mathrm{SE})$, with 13.1 per 100,000 women per year $( \pm 0.11 \mathrm{SE})$ and 1.7 per 100,000 men per year $( \pm 0.067 \mathrm{SE})$. No meaningful trends in incidence were observed over the 5-year study period (data not shown). Patient demographics and hospital characteristics are summarized in Tables 1 and 2 for female and male patients, respectively. Approximately $82 \%$ of GUFB presented between the ages of $18-55$. The highest number of cases were in the South (39\%) and Midwest $(22.3 \%)$ regions, and most cases presented to nonteaching (63.8\%) and urban hospitals (84.8\%). In addition, low income, lack of medical insurance or Medicaid insurance were found in $32.2 \%, 30.2 \%$, and $29.3 \%$ of cases, respectively.

\section{Female patients}

GUFB were more common in female patients, representing $89.5 \%$ of the cohort (91,645 patients). The majority of female patients presented during their reproductive years $(81.9 \%)$ and most commonly with a vulvar or vaginal foreign body (97.3\%). Urethral and bladder foreign bodies were less common and a significant portion of these patients were older than 55 years old $(24.5 \%)$.

The largest proportion of patients was seen in hospitals located in the South $(39.0 \%)$ followed by the Midwest $(22.3 \%)$, the Northeast $(21 \%)$ and the West region $(17.7 \%)$. The majority of female patients were evaluated in urban hospitals $(84.8 \%$ vs. $15.2 \%, p<0.01)$, and presented more frequently to non-trauma hospitals $(63.8 \%$ vs. $36.2 \%, p<$ $0.01)$. On the other hand, female patients with GUFB presented equally to teaching and nonteaching institutions (50.2\% vs. $49.8 \%, p=0.631)$.

A significant portion of female patients with GUFB had no insurance $(30.2 \%)$ or had Medicaid (29.3\%) as their primary insurance and $\sim 32.5 \%$ had a low-income level. The incidence of female patients presenting with GUFB was more common during the summer months $(p<0.01)$ and during weekends $(p<0.01)$ (Table 1).

\section{Male patients}

Male patients $(10,688)$ represented only $10.5 \%$ of the cohort. The most common location in male patients was the urethra and bladder $(50.6 \%)$ followed by penile foreign bodies $(44.6 \%)$. Penile foreign bodies refer only to those externally placed, such as objects inserted into the phallus or foreskin. Patients presenting with urethral and bladder foreign bodies were significantly older than those patients who presented with penile foreign bodies (42.0 years old vs. 34.3 years old, $p<0.01)$.

The largest proportion of patients was seen in hospitals located in the South (33.3\%) followed by the West $(29.1 \%)$, the Midwest $(21.2 \%)$, and the Northeast region $(16.4 \%)$. The majority of male patients were evaluated in urban ( $84.7 \%$ vs. $15.3 \%, p<0.01)$, non-trauma $(51.6 \%$ vs. $48.4 \%$, $p<0.01$ ), and presented to teaching hospitals $(52.5 \%$ vs. $47.5 .8 \%, p=0.001)$.

One third of male patients $(32.2 \%)$ had low-income level and a large portion of patients had no medical insurance $(35.9 \%)$, or had Medicaid $(20.8 \%)$ as their primary insurance. The incidence of GUFB in male patients was more common during the spring and summer months $(p<0.01)$, but it was not necessarily more common during weekends $(p=0.759)$.

\section{Gender differences}

Female patients with GUFB presented at a younger age compared with their male counterparts (mean age 28.9 years vs. 38.0 years, $p<0.01)$. However, female patients with urethral and bladder foreign bodies presented at an older age (mean age $40.7 \pm 0.5$ years old), similar to male patients. Male patients represented only one tenth $(10.5 \%)$ of the entire cohort. About one fifth (18.6\%) of male patients presented with Medicare coverage when compared with only $4.5 \%$ of female patients. Finally, GUFB presentations were more common during weekends in female patients, but not in males $(p=0.759)$.

\section{Hospital admissions, length of stay and healthcare costs}

The costs of ED evaluation averaged $\$ 3,769$ per patient with only $2.8 \%$ of patients (2861 pts) requiring hospital admission. Male patients were more commonly admitted than female patients $(21.1 \%$ vs. $0.6 \%, p<0.01)$. The mean length of stay for patients who were admitted was 3.4 days, with no difference between female and male patients (3.4 vs. 3.3 days, $p>0.891)$. Male patients with urethra/bladder foreign bodies stayed longer (average 3.58 days) and incurred a higher hospital charge (average \$30,839) than patients with penile foreign bodies (average \$27,479) or compared with female patients with vulvar/vaginal foreign bodies (average $\$ 18,879$ ) ( $p<0.01)$. The calculated annual national total healthcare cost for evaluating and managing patients with GUFB is $\$ 16,500,147$. 
Table 1 Characteristics of female patients presenting to the ED with a Genitourinary foreign body in the U.S. from 2010 to 2014

\begin{tabular}{|c|c|c|c|c|c|c|c|c|c|}
\hline \multirow[t]{2}{*}{ Characteristic } & \multicolumn{2}{|l|}{ Total } & \multicolumn{2}{|c|}{ Vulva/vaginal } & \multicolumn{2}{|c|}{ Urethra/bladder } & \multicolumn{2}{|c|}{ Other GU } & \multirow[t]{2}{*}{$P$ value } \\
\hline & $(N)$ & $\%$ & $(N)$ & $\%$ & $(N)$ & $\%$ & $(N)$ & $\%$ & \\
\hline Number of patients & 91,645 & $100.0 \%$ & 89,160 & $97.3 \%$ & 1738 & $1.9 \%$ & 746 & $0.8 \%$ & $<0.01$ \\
\hline Age in years $($ mean $\pm \mathrm{SE})$ & \multicolumn{2}{|c|}{$28.92 \pm 0.04$ years } & \multicolumn{2}{|c|}{$26.68 \pm 0.04$ years } & \multicolumn{2}{|c|}{$40.73 \pm 0.51$ years } & \multicolumn{2}{|c|}{$29.60 \pm 0.58$ years } & $<0.01$ \\
\hline $0-18$ & 14,315 & $15.6 \%$ & 13,941 & $15.6 \%$ & 221 & $12.7 \%$ & 153 & $20.5 \%$ & \\
\hline $18-55$ & 75,046 & $81.9 \%$ & 73,417 & $82.3 \%$ & 1091 & $62.8 \%$ & 538 & $72.1 \%$ & \\
\hline$>55$ & 2284 & $2.5 \%$ & 1802 & $2.0 \%$ & 427 & $24.5 \%$ & 55 & $7.4 \%$ & \\
\hline Hospital U.S. region & & & & & & & & & $<0.01$ \\
\hline Northeast & 19,258 & $21.0 \%$ & 18,861 & $21.2 \%$ & 243 & $14.0 \%$ & 154 & $20.6 \%$ & \\
\hline Midwest & 20,448 & $22.3 \%$ & 19,797 & $22.2 \%$ & 487 & $28.0 \%$ & 164 & $22.0 \%$ & \\
\hline South & 35,713 & $39.0 \%$ & 34,684 & $38.9 \%$ & 756 & $43.5 \%$ & 273 & $36.7 \%$ & \\
\hline West & 16,226 & $17.7 \%$ & 15,819 & - & 252 & $14.5 \%$ & 155 & $20.7 \%$ & \\
\hline Hospital teaching status & & & & & & & & & 0.631 \\
\hline Nonteaching & 45,606 & $49.8 \%$ & 44,205 & $49.6 \%$ & 990 & $57.0 \%$ & 410 & $55.0 \%$ & \\
\hline Teaching & 46,039 & $50.2 \%$ & 44,955 & $50.4 \%$ & 748 & $43.0 \%$ & 336 & $45.0 \%$ & \\
\hline Trauma hospital status & & & & & & & & & $<0.01$ \\
\hline Non-trauma & 58,476 & $63.8 \%$ & 57,013 & $63.9 \%$ & 995 & $57.3 \%$ & 467 & $62.6 \%$ & \\
\hline Trauma level 1-3 & 33,169 & $36.2 \%$ & 32,147 & $36.1 \%$ & 743 & $42.7 \%$ & 279 & $37.4 \%$ & \\
\hline Hospital location & & & & & & & & & $<0.01$ \\
\hline Rural & 13,960 & $15.2 \%$ & 13,548 & $15.2 \%$ & 296 & $17.0 \%$ & 117 & $15.6 \%$ & \\
\hline Urban & 77,685 & $84.8 \%$ & 75,612 & $84.8 \%$ & 1443 & $83.0 \%$ & 630 & $84.4 \%$ & \\
\hline Primary insurance & & & & & & & & & $<0.01$ \\
\hline Medicare & 4104 & $4.5 \%$ & 3578 & $4.0 \%$ & 453 & $26.1 \%$ & 73 & $9.8 \%$ & \\
\hline Medicaid & 26,795 & $29.3 \%$ & 25,975 & $29.2 \%$ & 567 & $32.7 \%$ & 252 & $33.8 \%$ & \\
\hline Private & 32,880 & $36.0 \%$ & 32,183 & $36.2 \%$ & 434 & $25.0 \%$ & 263 & $35.3 \%$ & \\
\hline No insurance (e.g., self-pay/other) & 27,569 & $30.2 \%$ & 27,131 & $30.5 \%$ & 281 & $16.2 \%$ & 158 & $21.1 \%$ & \\
\hline Income & & & & & & & & & $<0.01$ \\
\hline Low & 29,258 & $32.5 \%$ & 28,532 & $32.6 \%$ & 482 & $28.5 \%$ & 244 & $32.8 \%$ & \\
\hline Not low & 60,670 & $67.5 \%$ & 58,961 & $67.4 \%$ & 1211 & $71.5 \%$ & 499 & $67.2 \%$ & \\
\hline Weekend presentation & 34,583 & $37.7 \%$ & 33,817 & $37.9 \%$ & 503 & $28.9 \%$ & 263 & $35.3 \%$ & $<0.01$ \\
\hline Season of presentation & & & & & & & & & $<0.01$ \\
\hline Winter & 21,419 & $23.4 \%$ & 20,967 & $23.5 \%$ & 335 & $19.3 \%$ & 117 & $15.7 \%$ & \\
\hline Spring & 23,541 & $25.7 \%$ & 22,902 & $25.7 \%$ & 402 & $23.1 \%$ & 237 & $31.8 \%$ & \\
\hline Summer & 24,919 & $27.2 \%$ & 24,223 & $27.2 \%$ & 475 & $27.3 \%$ & 221 & $29.6 \%$ & \\
\hline Fall & 21,723 & $23.7 \%$ & 21,026 & $23.6 \%$ & 527 & $30.3 \%$ & 170 & $22.8 \%$ & \\
\hline
\end{tabular}

$P$-values were calculated using the Chi-square test

\section{Mental health}

Table 3 summarizes the association of GUFB and mental health disorders. Mental health disorders were six times more common in male patients when compared with female patients $(36.0 \%$ vs. $6.1 \%, p<0.01)$. Mental health disorders were more commonly associated with urethral and bladder foreign bodies as compared with penile foreign bodies (60.0\% vs. $33.4 \%, p<0.01)$.

Approximately $6 \%$ of female patients with GUFB had a psychiatric diagnosis. However, among these patients up to 23.6\% had multiple comorbid mental health disorders with mood disorders being the most frequent diagnosis. In contrast, $44 \%$ of male patients had multiple mental health disorders, with near equal prevalence of schizophrenia, mood disorders, and other unspecified psychotic disorders $(\sim 10 \%)$.

\section{Discussion}

The GUFB literature is limited to case reports, technique papers, and small series [4-7]. Van Ophoven et al. presented the largest review to date [8]. Though the overall 
Table 2 Characteristics of male patients presenting to the ED with a Genitourinary Foreign Body in the U.S. from 2010 to 2014

\begin{tabular}{|c|c|c|c|c|c|c|c|c|c|}
\hline \multirow[t]{2}{*}{ Characteristic } & \multicolumn{2}{|l|}{ Total } & \multicolumn{2}{|l|}{ Penile } & \multicolumn{2}{|c|}{ Urethra/bladder } & \multicolumn{2}{|c|}{ Other GU } & \multirow[t]{2}{*}{$P$ value } \\
\hline & $(N)$ & $\%$ & $(N)$ & $\%$ & $(N)$ & $\%$ & $(N)$ & $\%$ & \\
\hline Number of patients & 10,688 & $100.0 \%$ & 4762 & $44.6 \%$ & 5413 & $50.6 \%$ & 513 & $4.8 \%$ & $P<0.01$ \\
\hline Age in years $($ mean $\pm \mathrm{SE})$ & \multicolumn{2}{|c|}{$38.01 \pm 0.19$ years } & \multicolumn{2}{|c|}{$34.37 \pm 0.28$ years } & \multicolumn{2}{|c|}{$41.98 \pm 0.27$ years } & \multicolumn{2}{|c|}{$29.95 \pm 0.93$ years } & $P<0.01$ \\
\hline $0-9$ & 786 & $7.4 \%$ & 534 & $11.2 \%$ & 136 & $2.5 \%$ & 116 & $22.6 \%$ & \\
\hline 10-19 & 1069 & $10.0 \%$ & 479 & $10.1 \%$ & 531 & $9.8 \%$ & 58 & $11.4 \%$ & \\
\hline $20-29$ & 2256 & $21.1 \%$ & 1116 & $23.4 \%$ & 1051 & $19.4 \%$ & 89 & $17.3 \%$ & \\
\hline $30-39$ & 2080 & $19.5 \%$ & 951 & $20.0 \%$ & 1025 & $18.9 \%$ & 104 & $20.3 \%$ & \\
\hline $40-49$ & 1611 & $15.1 \%$ & 681 & $14.3 \%$ & 864 & $16.0 \%$ & 66 & $12.8 \%$ & \\
\hline $50-59$ & 1182 & $11.1 \%$ & 453 & $9.5 \%$ & 699 & $12.9 \%$ & 29 & $5.7 \%$ & \\
\hline $60-69$ & 861 & $8.1 \%$ & 334 & $7.0 \%$ & 508 & $9.4 \%$ & 20 & $3.8 \%$ & \\
\hline $70-79$ & 392 & $3.7 \%$ & 88 & $1.9 \%$ & 291 & $5.4 \%$ & 13 & $2.6 \%$ & \\
\hline$>80$ & 450 & $4.2 \%$ & 124 & $2.6 \%$ & 308 & $5.7 \%$ & 18 & $3.4 \%$ & \\
\hline Hospital U.S. region* & & & & & & & & & $P<0.01$ \\
\hline Northeast & 1757 & $16.4 \%$ & 813 & $17.1 \%$ & 868 & $16.0 \%$ & 76 & $14.9 \%$ & \\
\hline Midwest & 2268 & $21.2 \%$ & 985 & $20.7 \%$ & 1153 & $21.3 \%$ & 130 & $25.3 \%$ & \\
\hline South & 3554 & $33.3 \%$ & 1591 & $33.4 \%$ & 1770 & $32.7 \%$ & 194 & $37.8 \%$ & \\
\hline West & 3108 & $29.1 \%$ & 1373 & $28.8 \%$ & 1622 & $30.0 \%$ & 113 & $22.0 \%$ & \\
\hline Hospital teaching status & & & & & & & & & $P<0.01$ \\
\hline Nonteaching & 5082 & $47.5 \%$ & 2465 & $51.8 \%$ & 2342 & $43.3 \%$ & 276 & $53.7 \%$ & \\
\hline Teaching & 5606 & $52.5 \%$ & 2297 & $48.2 \%$ & 3071 & $56.7 \%$ & 237 & $46.3 \%$ & \\
\hline Trauma hospital status & & & & & & & & & $P<0.01$ \\
\hline Non-trauma & 5519 & $51.6 \%$ & 2487 & $52.2 \%$ & 2703 & $49.9 \%$ & 328 & $64.0 \%$ & \\
\hline Trauma level 1-3 & 5169 & $48.4 \%$ & 2275 & $47.8 \%$ & 2710 & $50.1 \%$ & 185 & $36.0 \%$ & \\
\hline Hospital location & & & & & & & & & $P<0.01$ \\
\hline Rural & 1640 & $15.3 \%$ & 815 & $17.1 \%$ & 737 & $13.6 \%$ & 88 & $17.2 \%$ & \\
\hline Urban & 9048 & $84.7 \%$ & 3947 & $82.9 \%$ & 4676 & $86.4 \%$ & 425 & $82.8 \%$ & \\
\hline Primary payer & & & & & & & & & $P<0.01$ \\
\hline Medicare & 1986 & $18.6 \%$ & 685 & $14.4 \%$ & 1250 & $23.2 \%$ & 51 & $10.1 \%$ & \\
\hline Medicaid & 2214 & $20.8 \%$ & 1018 & $21.4 \%$ & 1075 & $19.9 \%$ & 121 & $23.9 \%$ & \\
\hline Private & 2631 & $24.7 \%$ & 1163 & $24.5 \%$ & 1316 & $24.4 \%$ & 152 & $29.9 \%$ & \\
\hline No insurance (e.g., self-pay/other) & 3822 & $35.9 \%$ & 1882 & $39.6 \%$ & 1757 & $32.6 \%$ & 183 & $36.0 \%$ & \\
\hline Income & & & & & & & & & $P<0.01$ \\
\hline Low & 3110 & $32.2 \%$ & 1412 & $33.0 \%$ & 1532 & $31.3 \%$ & 167 & $34.9 \%$ & \\
\hline Not low & 6550 & $67.8 \%$ & 2870 & $67.0 \%$ & 3369 & $68.7 \%$ & 311 & $65.1 \%$ & \\
\hline Weekend presentation & 2941 & $27.5 \%$ & 1376 & $28.9 \%$ & 1435 & $26.5 \%$ & 130 & $25.3 \%$ & 0.759 \\
\hline Season of presentation & & & & & & & & & \\
\hline Winter & 2306 & $21.6 \%$ & 997 & $20.9 \%$ & 1200 & $22.2 \%$ & 110 & $21.4 \%$ & $P<0.01$ \\
\hline Spring & 2782 & $26.0 \%$ & 1327 & $27.9 \%$ & 1371 & $25.3 \%$ & 84 & $16.4 \%$ & \\
\hline Summer & 2874 & $26.9 \%$ & 1250 & $26.3 \%$ & 1456 & $26.9 \%$ & 168 & $32.7 \%$ & \\
\hline Fall & 2711 & $25.4 \%$ & 1182 & $24.8 \%$ & 1381 & $25.5 \%$ & 147 & $28.7 \%$ & \\
\hline
\end{tabular}

number of cases was large, this study was more a descriptive collection of interesting case reports, rather than a systematic analysis of patterns with these patients. In consequence, the epidemiology, medical and socioeconomic risk factors, seasonality, geographical distribution, and the economic impact of GUFB are poorly understood.

Our goal was to provide a complete and thorough epidemiological picture of GUFB and the strength of databasecentered research lies in the volume of cases available for 


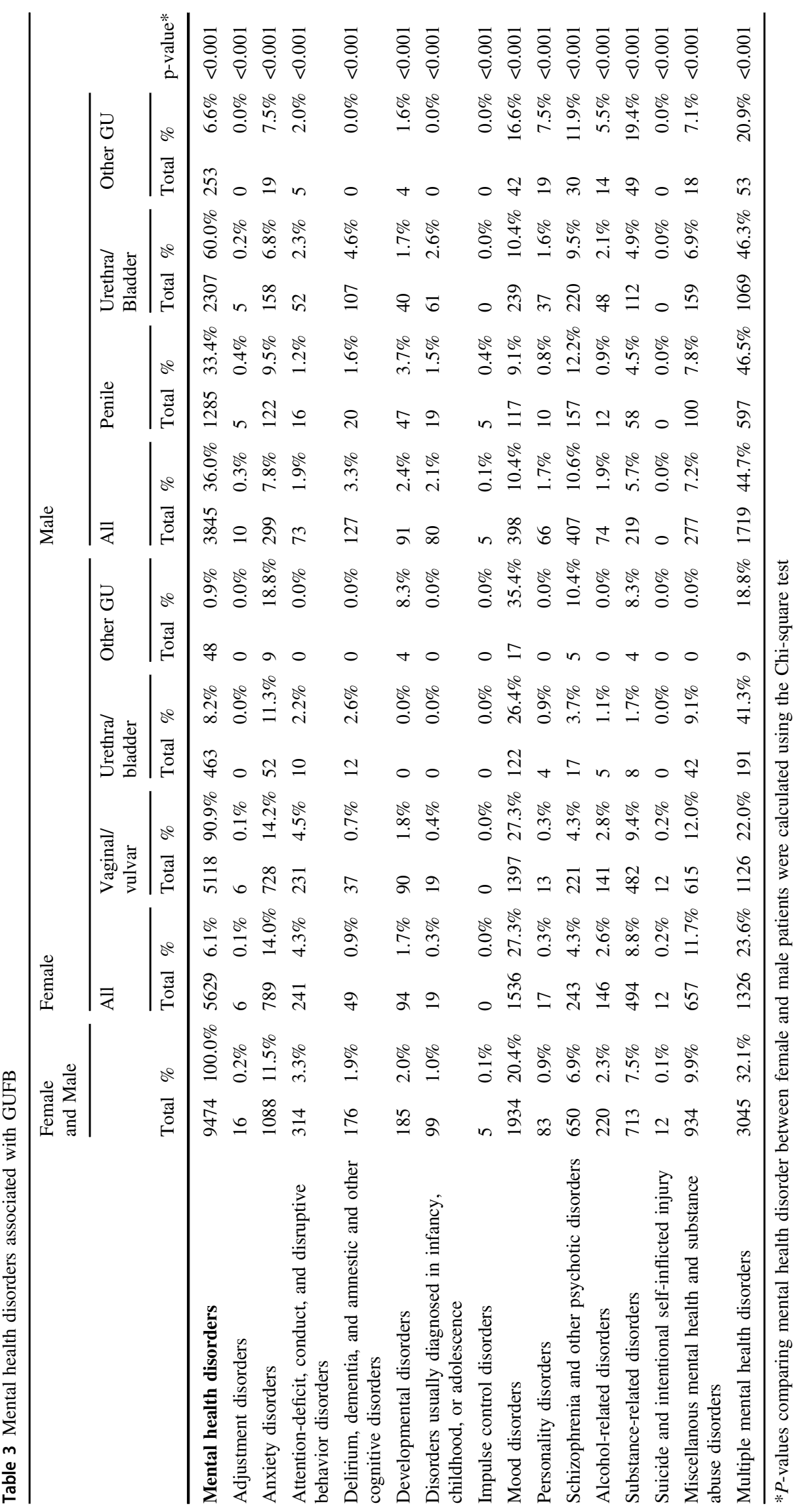


analysis. That increased volume leads to significant heterogeneity, as is evidenced by the diverse anatomic locations of GUFB. Given the overwhelming predominance of vulvo/ vaginal GUFB in younger women of reproductive age, our theory is that a substantial contributor may be contraceptive devices or feminine hygiene products. Unfortunately, the NEDS database does not provide data on the specific type of foreign bodies that is retained. A careful review of the literature, however, does substantiate that most of the vulvo/ vaginal foreign bodies are contraceptive devices (IUDs, diaphragms, etc.), menstruation management products such as tampons, or devices for prolapse (pessaries) [16-20]. This may account for some of the gender differences in GUFB, although female patients with urethral or bladder foreign bodies more closely resemble their male counterparts in age and comorbid mental health conditions.

Only $4.68 \%$ of GUFB cases resulted in admission to the hospital, and we believe that this low admission rate is due to the successful management in the emergency room or subsequent outpatient clinic management [21]. Among those who were admitted, however, there was a disproportionately higher incidence of males $(24.8 \%$ vs. $2.1 \%$, $p<0.001$ ). This phenomenon may be explained by the higher morbidity of urethral or bladder foreign bodies, which often necessitate endoscopic or surgical intervention. By the same token, when female cases of bladder and urethral foreign bodies were evaluated, the admission rates were quite similar between genders.

Most patients with GUFB presented during the summer months, in the South (39.6\%) and in the Midwest (22.6\%). Females with GUFB more frequently presented during weekends when compared with males. We currently do not have an explanation for the seasonality or geographical distribution of GUFB.

We did not detect any association between low income status and GUFB. According to an analysis of the 2011 data from the U.S. Census Bureau's American Community Survey, the number of low-income working families is $\sim 10.4$ million, representing nearly one-third of all working families, which matches the percentages noted in our study. In contrast, we did find high rates of uninsured patients presenting with GUFB (30\% and 36\% for males and females, respectively), which are unequivocally higher than the national average $(15.7 \%$ in 2011 down trending to $10.4 \%$ in 2014) [22]. While we cannot offer an explanation for this occurrence, the healthcare costs incurred by uninsured individuals may impose an added burden to hospital systems.

The health care costs associated with ophthalmologic, respiratory, and alimentary tract foreign bodies have been studied in the past, but efforts evaluating the genitourinary tract are lacking $[2,3]$. We report that the calculated annual national total healthcare cost for evaluating and managing patients with GUFB to be $\$ 16,500,147$, with the highest cost incurred by patients with urethra/bladder foreign bodies. GUFB poses a significant cost to our healthcare system and the association with mental health issues suggests that the behavioral risk aspect may not be entirely modifiable.

Mental health disorders have been anecdotally associated with GUFB [9]. Rahman et al. reported on 17 men treated for urinary foreign bodies in 17 years, revealing psychiatric illness as the most common reason for insertion [23]. Similarly, Rieder et al. presented a 10-year series of 13 patients (11 men and 2 women), who had both self-inflicted, accidental, and iatrogenic foreign bodies in the genitourinary tract [24]. Our data appears to be in line with these historical case series, but with the new revelation of male preponderance. Moreover, we noted a tendency of mental disorders to coincide with foreign body insertion into the urethra or bladder, in contrast to the vagina or penis.

The strength in this approach is the sheer volume of patient records that can be analyzed in a pooled fashion. This approach allows us to explore this topic in greater depth than previous case reports and case series. Our source database also contains a diverse set of insurers, adding to the overall strength. Health care databases, however, are contingent upon accurate recording and appropriate matching of charge codes to the patient's diagnosis and treatment. As such, the patient motivation for GUFB insertion was not available. Similarly, the actual object, exact placement location, and extraction method are not available in this analysis. Further patient outcomes such as follow-up visits, readmissions, and repeat episodes are also not available. Given the cross sectional, observational nature of the study, no conclusions can be made regarding causality. Other limitations include the retrospective observational nature of this study. It is particularly important to point out that results of a large study population are more likely to show small differences among subgroups, and results achieving minimal significant differences must be interpreted within a clinical context. Despite these weaknesses, our manuscript reveals novel findings regarding the epidemiology of GUFB in both men and women.

\section{Conclusions}

This is the first and largest population-based study investigating the epidemiology of genitourinary foreign bodies. GUFB have a significant impact on healthcare resources. In addition, GUFB are more common in younger women and the majority of them are vulvar/vaginal. Penile and urethral/ bladder foreign bodies occurred in older male patients and were associated with longer hospital stays and hospital costs. Over one third of male patients with urethra/bladder foreign bodies had significant mental health disorders. 
Funding This work is supported in part by NIH grant K12 DK0083014, the Multidisciplinary K12 Urologic Research (KURe) Career Development Program awarded to Dolores J. Lamb (NT is a K12 Scholar).

\section{Compliance with ethical standards}

Conflict of interest Both RM and MSG work as Coloplast consultants.

Publisher's note Springer Nature remains neutral with regard to jurisdictional claims in published maps and institutional affiliations.

\section{References}

1. Palmer CJ, Houlihan M, Psutka SP, Ellis KA, Vidal P, Hollowell CM. Foreign bodies: clinical presentation and management. Urology. 2016;97:257-60.

2. Brunner J, Russel M, Herr K, Benjamin E, Myers L, Boyko O, et al. Nonsuicidal self-injury-related foreign bodies in the emergency department. Semin Ultrasound CT MR. 2015;36:80-7.

3. Srppnath J, Mahendrakar V. Management of tracheo bronchial foreign bodies-a retrospective analysis. Indian J Otolaryngol Head Neck Surg. 2002;54:127-31.

4. Buca DI, Tizio LD, Ianieri MM, Murgano Daniela, Leombroni Martina, Liberati Marco. Peritonitis due to a foreign vaginal body: a case report. J Obstet Gynaecol. 2016;36:690-1.

5. Kurzel RB, Chaudhuri G, Hall D. Management of a vaginal foreign body. Ann Emerg Med. 1981;10:492-3.

6. MacCraith E, Davis NF, Forde J. Unusual genitourinary tract activity. BMJ Case Rep. 2017;2017.

7. Mastromichalis M, Sackman D, Tycast JF, Chehval MJ. Urethral foreign body insertion for secondary gain in the incarcerated population. Can J Urol. 2011;18:5916-7.

8. Van Ophoven A, deKernion JB. Clinical management of foreign bodies of the genitourinary tract. J Urol. 2000;164:274-87.

9. Alkan E, Basar MM, Endourological treatment of foreign bodies in the urinary system. JSLS, 2014.18.

10. Kenney RD. Adolescent males who insert genitourinary foreign bodies: is psychiatric referral required?. Urology. 1988;32:127-9.

11. Agency for Healthcare Research and Quality. Healthcare cost and utilization project (HCUP). Agency for Healthcare Research and Quality; 2018. https://www.hcup-us.ahrq.gov/nedsoverview.jsp.
12. World Health Organization. International classification of diease: $\left[9^{\text {th }}\right]$ ninth revision, basic tabulation list with alphabetic index. World Health Organization; 1978. http://www.who.int/iris/handle/ $10665 / 39473$

13. Cheung ML, Rezai S, Jackman JM, Patel ND, Bernaba BZ, Hakimian $\mathrm{O}$, et al. Retained intrauterine device (IUD): triple case report and review of the literature. Case Rep Obstet Gynecol. 2018;2018:9362962.

14. Closson FT, Lichenstein R. Vaginal foreign bodies and child sexual abuse: an important consideration. West J Emerg Med. 2013;14:437-9.

15. Owens P, Myers M. Care of Adults With Mental Health and Substance Abuse Disorders in U.S. Community Hospitals, 2004-HCUP Fact Book No. 10. https://archive.ahrq. gov/data/hcup/factbk10/factbk10a.htm. Accessed 5 September 2019.

16. Andrikopoulou M, Lazarou G. Rare case of neglected pessary presenting with concealed vaginal hemorrhage. Female Pelvic Med Reconstr Surg. 2015;21:e1-2.

17. Berger FH, Nieboer KH, Goh GS, Pinto A, Scaglione M. Body packing: a review of general background, clinical and imaging aspects. Radio Med. 2015;120:118-32.

18. Jacobs I, Lloyd GL. Endoscopic removal of a retained intravesical tampon using lubricant. J Endourol. 2012;26:45-6.

19. Kochakarn W, Pummanagura W. Foreign bodies in the female urinary bladder: 20-year experience in Ramathibodi Hospital. Asian J Surg. 2008;31:130-3.

20. Pierce EH. Retained vaginal tampon: a unique cause of acute abdomen. South Med J. 1973;66:640. contd

21. Mannan A, Anwar S, Qayyum A, Tasneem RA. Foreign bodies in the urinary bladder and their management: a Pakistani experience. Singap Med J. 2011;52:24-8.

22. Smith JC, Medalia C. Health Insurance Coverage in the United States: 2014. https://www.census.gov/library/publications/2015/ demo/p60-253.html U.S. Government Printing Office, Washington, DC 2015.

23. Rahman NU, Elliott SP, McAninch JW. Self-inflicted male urethral foreign body insertion: endoscopic management and complications. BJU Int. 2004;94:1051-3.

24. Rieder J, Brusky J, Tran V, Stern K, Aboseif S. Review of intentionally self-inflicted, accidental and iatrogetic foreign objects in the genitourinary tract. Urol Int. 2010;84:471-5. 